\title{
Research on Rolling Mill Vibration Based on the Rolling Piece Hysteretic Nonlinear Deformation
}

\author{
Dongxiao Hou ${ }^{1, a}$, Fei Liu' ${ }^{2}$, Haoran $\mathrm{Liu}^{2}$, Rongrong Peng ${ }^{2}$ and Yue $\mathrm{Zhu}^{3}$ \\ ${ }^{1}$ College of Control Engineering, Northeast University at Qinhuangdao, Qinhuangdao 066004, \\ China \\ ${ }^{2}$ Institute of Information Technology and Engineering, Yanshan University, Qinhuangdao 066004, \\ China \\ ${ }^{3}$ Institute of Electrical Engineering, Yanshan University, Qinhuangdao 066004, China \\ ahoudongxiao1982@163.com
}

Keywords: Rolling Mill; Hysteretic; Vibration

Abstract. The Bonc-Wen hysteretic model was used describe the rolling piece elastic-plastic deformation process performance of hysteretic characteristics, this hysteretic characteristic considered in the rolling process, vertical vibration model of hysteretic nonlinear of the strip mill roll system is established. Analyzed the rule of rolled piece deformation process change, and used different parameters incentive coefficients of rolled piece deformation hysteretic force. Then found the deformation process of rolled piece expressed hysteretic nonlinear characteristic when the roll system interference by the cycle motivation. Analyzed the effect law on the stability of the system, and get the vibration status of system in different conditions, which provides theory basis for further control the nonlinear rolling mill vibration behavior, gave some advices on reducing the vibration.

\section{Introduction}

The vertical vibration of the strip mill is always the technical problem influence the surface quality of the production and the stability of rolling process. The occurrence of this vibration will not only emerge light and shade stripe in the surface of rolled piece, caused thickness volatility and error, influence the quality of rolling product, but also make the roll surface produces marks and accelerate roller surface wear, even broken strip or damage the equipment [1]. In the studying of strip mill vertical vibration, the equivalent simplification to elastic-plastic deformation process directly affects the precision of the vibration model. In Ref.[2] and [3], used elastic component with linear stiffness to equivalent rolling piece elastic-plastic deformation process, and established the linear vertical vibration model of mill to research mill vibration problem; In Ref. [4], the elastic-plastic deformation process of rolled piece was considered as Duffing form to study mill vibration problems; In Ref. [5], in consideration of periodic disturbance to the mill when equivalent stiffness of rolled piece occur cyclical change, established vibration model of parametric excitation to study rolling mill and resonance phenomenon and the stability of it. Actually, rolled piece of elastic-plastic deformation process is one kind of nonlinear deformation process with the hysteretic characteristic[6-7], so we should launch research on the hysteretic characteristic of rolled piece and the influence to the rolling mill vibration.

In this paper, based on consideration of the characteristics deformation process of the rolled piece, used the Bonc-Wen hysteretic model describe the elastic-plastic deformation process of rolled piece, established the hysteretic nonlinear dynamic vibration model of the strip mill. Analyzed the rolled piece deformation characteristics and the parameters incentive coefficients influence the system under the cycle motivation, at the same time, studied the characteristics of vertical vibration system with the amplitude of the motivation for changes, got conditions of the system in different vibration behavior, in order to provide certain theoretical reference to research and suppress the mill vibration.

\section{Hysteretic nonlinear vibration model of strip mill}


During the actual production, strip rolling process can be abstracted and simplified as shown in figure 1 .

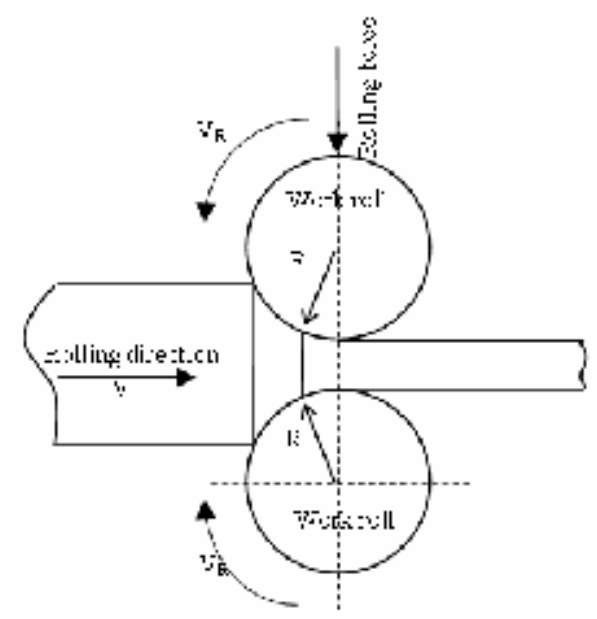

Figure 1 simplified model of rolling process

Due to the complexity of the equipment and raising of steel rolling speed, some factors inevitably leading to the rolling force fluctuate in the rolling process, rolling force fluctuate will make rolled piece in the alternating between loading and unloading, rolled piece yield limit changing in the plastic deformation stage, make the loading and unloading curve can't coincide. In this case, the roll force expressed hysteretic characteristic. Bonc-Wen model consists of nonlinear damping and nonlinear stiffness, can descript various hysteretic curves better, and has good application in engineering. Apply to describe elastic-plastic deformation with the process of back and forth. Therefore, the Bonc-Wen model used to describe the nonlinear roll force of rolled piece in rolling process, its specific form as follows:

$$
F_{z}=z
$$

$$
\&=A \&-\left.\alpha|x| z\right|^{n-1} z-\left.\beta \notin z\right|^{n}
$$

$F_{\mathrm{z}}$ express roll force with hysteretic characteristic, which depend on expression (2), the shape of the hysteretic loop controlled by $A, \alpha, \beta$ and $\mathrm{n}$.

According to structure's symmetry of the mill roll system, considered rolled piece hysteretic deformation characteristics and the stiffness changing with the external excitation, established single degree of freedom mill roll system vertical vibration mechanics model as shown in figure 2.

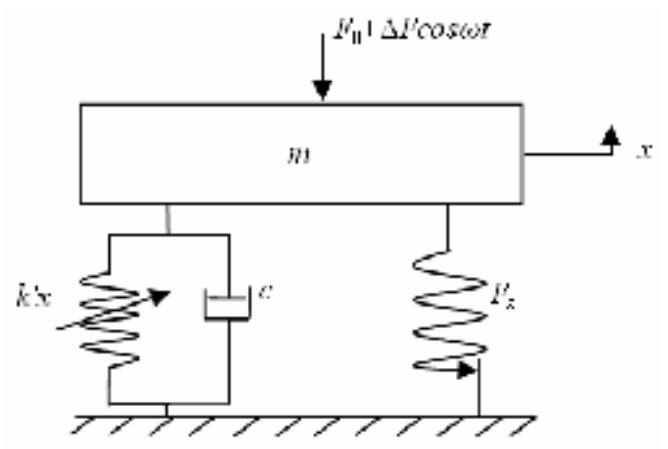

Figure 2 vertical vibration mechanics model of roll system

Among them, $\mathrm{m}$ is the equivalent quality of the upper roll system; $F_{0}$ is roll force; $\Delta F \cos \omega t$ is fluctuation of roll force when it suffers some external disturbance. In practical rolling process, the equivalent stiffness of rolled piece changing along with external incentive, used $k^{\prime}=k(1+\sigma \cos \omega t)$ express the equivalent stiffness of rolled piece under the influence of outer incentive.

From vertical vibration mechanics model of roll system showed in figure 2, the dynamic equation about hysteretic nonlinear vibration system can be got as follow 
$m+k(1+\sigma \cos \omega t) x+F_{z}=F_{0}+\Delta F \cos \omega t$

Expression (3) also can write as follow

$\xi_{x} \&+\omega_{0}^{2}(1+\sigma \cos \omega t) x+F_{z}^{\prime}=F_{0}^{\prime}+\Delta F^{\prime} \cos \omega t$

Among them, $x$ is vibration displacement of work roll in vertical direction,

$\omega_{0}=\sqrt{\frac{k}{m}}, \xi=\frac{c}{m}, F_{z}^{\prime}=F_{z} / m, F_{0}^{\prime}=F_{0} / m, \Delta F^{\prime}=\Delta F / m$.

By expression (1) (2) and (4) can get the mill vibration dynamic equation as following:

$$
\left\{\begin{array}{l}
\&=y \\
\&=F_{0}^{\prime}+\Delta F^{\prime} \cos \omega t-\omega_{0}(1+\sigma \cos \omega t) x-\xi x \&-F_{z}^{\prime} \\
\&=k_{1}\left(A y-\left.\alpha|y| z\right|^{n-1} z-\beta y|z|^{n}\right)
\end{array}\right.
$$

Expression (5) is the hysteretic nonlinear vibration model of the strip rolling mill, is also the basic to further study nonlinear vibration.

\section{Rolled piece hysteretic deformation characteristic analyses}

In rolling process, roll force will produce a periodic fluctuation when suffer some external incentive effects, in this case, the elastic-plastic deformation process of rolled piece consist of two smooth curve (as shown in figure 3), used Bonc-Wen model can describe the hysteretic characteristic of roll force well.

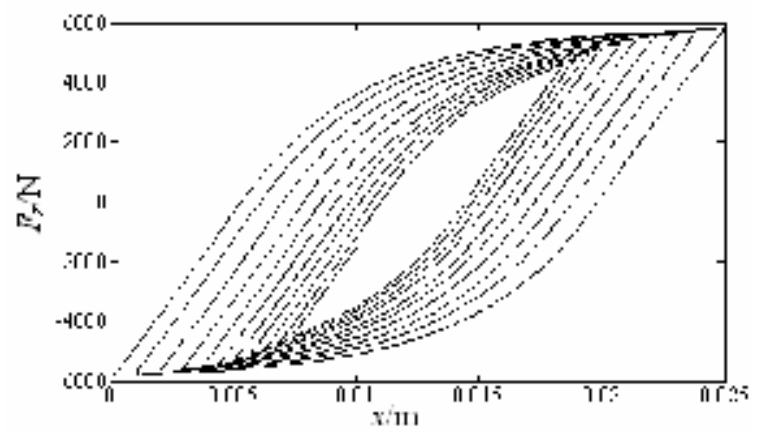

Figure 3 Hysteretic loop of rolled piece deformation

A factory 1780 mill practical parameters as an example, take $m=1.4432 \times 10^{5} \mathrm{~kg}, k=2.35 \times 10^{10} \mathrm{~N} / \mathrm{m}$, $\omega=450 \mathrm{rad} / \mathrm{s}$, got phase diagram of the system under external disturbance and hysteretic force curve of the rolled piece during deformation (as shown in figure 4). The figure 4 showed the hysteretic force reduced gradually with the system vibration amplitude attenuation weakening. 


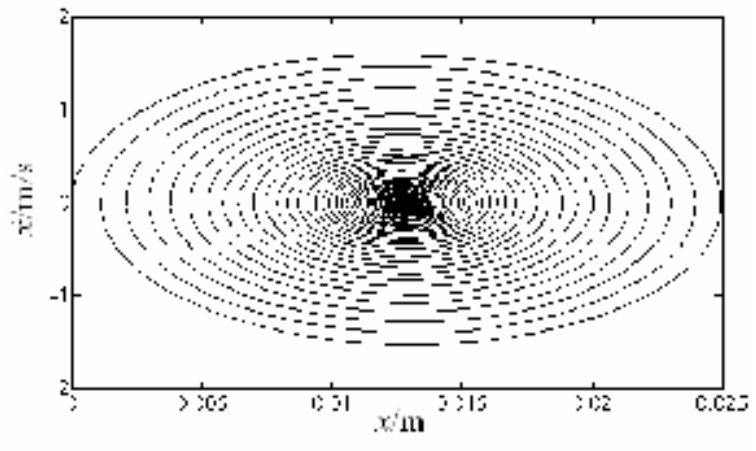

(a) Phase diagraul

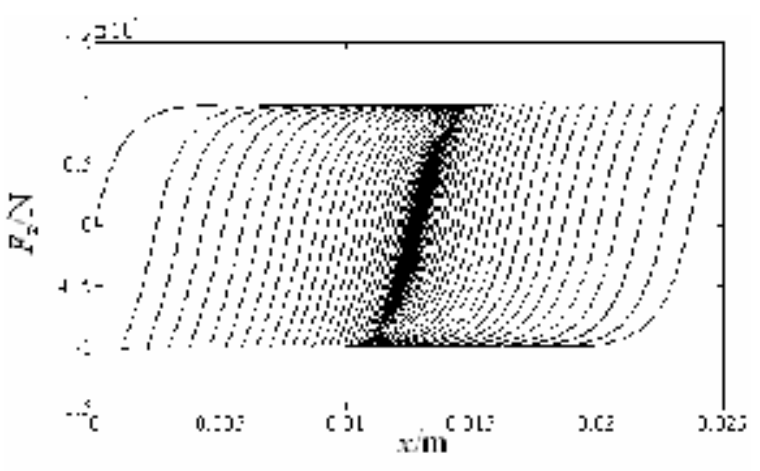

(b) Hysteretic loop

Figure 4 System response when $\sigma=0.05$

In order to get the external incentives change influence on the hysteretic force, increase coefficient of parameter incentive, can get the phase diagram and the hysteretic force curve as figure 6 shown.

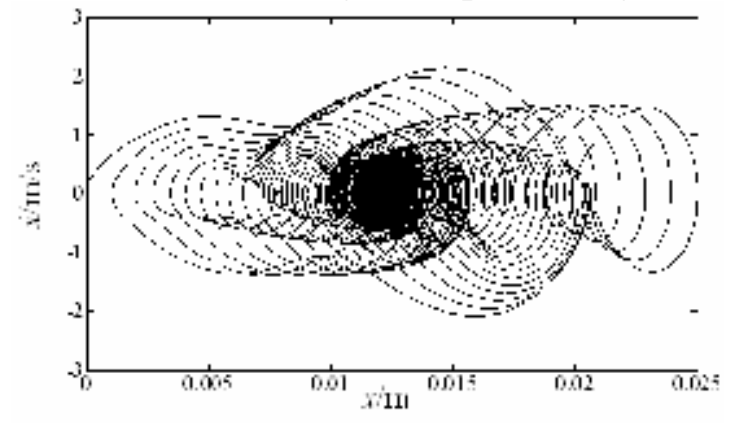

(a) Pline diriglaul

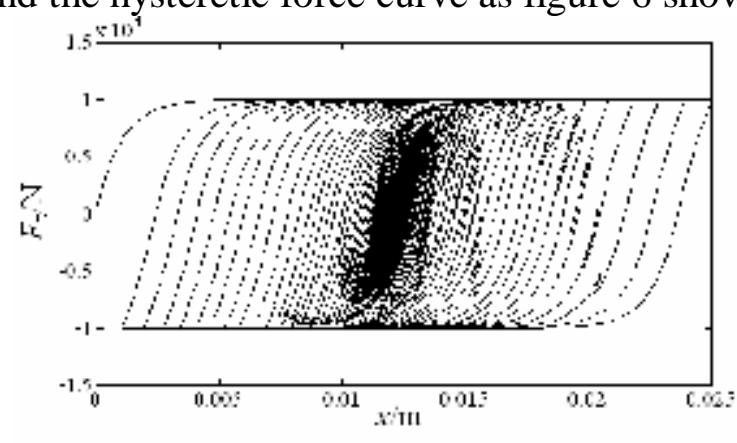

(b) Hyaktelis loge

Figure 5 System response when $\sigma=2$

Through the comparison between figure 4 and figure 5 , found hysteretic force decreased gradually along the hysteretic loop when the parameters incentive coefficient $\sigma=0.05$, but when the parameters incentive coefficient increases to $\sigma=2$, hysteretic force influence the roll system vibration and produced a fluctuation by itself, the shape of the hysteretic loop showed different form under different degree external incentive effect.

\section{Conclusions}

This paper considered elastic-plastic deformation characteristics of rolled piece, based on Bonc-Wen model established the hysteretic nonlinear vertical vibration model of strip mill, analyze the hysteretic deformation characteristic and the influence law to the vibration of roll system, and got the following conclusion.

\section{Acknowledgements}

The work was supported by National Natural Science Foundation of China through Project number 51105324, Natural Science Foundation of Heilongjiang Province of China through Project number E2011203069 and Fundamental Research Funds for the Central Universities through Project number N110323008, which are gratefully acknowledged.

\section{References:}

[1] Tamiya T, Furui K, Lida H, et al. Analysis of chattering phenomenon in cold rolling [J]. In: ISIJ ed. Proceedings of the International Conference on Steel Rolling, Tokyo. 1980,1191-1202.

[2] Yarita I, Furukawa K, seino Y. An analysis of chattering in cold rolling of ultra thin gauge steel strip [J]. Transactions ISU, 1979, 19(1):1-10. 
[3] Meng Lingqi, Du Yong, Ma Shengbiao, et al. Non-linearity of vertical vibration of medium plate mill [J]. Journal of Jilin University (Engineering and Technology Edition), 2009, 39(3):712-715.

[4] Hou Dongxiao, Chen Hao, Liu Bin, et al. Analysis on parametrically excited nonlinear vertical vibration of roller system in rolling mills [J]. Journal of Vibration and Shock, 2009, 28(11):1-5.

[5] Li Hongguang, Meng Guang. Nonlinear dynamics of a SDOF oscillator with Bouc-Wen hysteresis [J]. Chaos, Solitons and Fractals 34 (2007) 337-343.

[6] Jan Awrejcewicz , Larisa Dzyubak , Claude-Henri Lamarque. Modelling of hysteresis using Masing-Bouc-Wen's framework and search of conditions for the chaotic responses [J]. Communications in Nonlinear Science and Numerical Simulation 13 (2008) 939-958.

[7] A.E. Charalampakis, V.K. Koumousis. A Bouc-Wen model compatible with plasticity postulates [J]. Journal of Sound and Vibration, 322 (2009) 954-968. 